\title{
THE EFFECTS OF MOLECULAR AND PROCESSING PARAMETERS ON ENERGY HARVESTING CAPABILITY OF PVDF-BASED NANOGENERATORS
}

\author{
${ }^{1}$ Martin CVEK, ${ }^{1}$ Josef OSIČKA, ${ }^{1}$ Peter SRNEC, ${ }^{1}$ Miroslav MRLÍK, ${ }^{2}$ Pavel TOFEL \\ ${ }^{1}$ Tomas Bata University in Zlín, University Institute, Centre of Polymer Systems, Zlín, Czech Republic, EU, \\ cvek@utb.cz \\ ${ }^{2}$ Brno University of Technology, Department of Physics, Faculty of Electrical Engineering and \\ Communication, Brno, Czech Republic, EU
}

https://doi.org/10.37904/nanocon.2020.3720

\begin{abstract}
In the research of the alternative vibration sensing systems, the major potential is attributed to piezoelectric materials that can generate the electrical output from the waste vibration sources of the industrial machines. Poly(vinylidene fluoride) (PVDF), mostly in the electroactive $\beta$-phase, is a great option due to its excellent piezoelectric properties and good flexibility. The $\beta$-phase PVDF can be obtained by simple stretching of the $\alpha$ phase PVDF films, and the conditions of this process are well documented. Surprisingly, the implications of molecular parameters of the PVDF have not been addressed yet. This study investigates the effect of the molecular weight $(\mathrm{Mw})$ of the PVDF on the $\beta$-phase development and consequential vibration sensing capabilities after uniaxial stretching. The successful phase transformation was confirmed using FTIR and XRD. In the FTIR spectra, a typical $\alpha$-phase peak at $762 \mathrm{~cm}^{-1}$ diminished giving rise to the $\beta$-phase peak at $840 \mathrm{~cm}^{-1}$ after the stretching. The results also showed a remarkable impact of the Mw on d33 coefficient making $\mathrm{Mw}$ an important parameter that should not be overlooked in designing the PVDF-based sensing elements. The obtained data are highly important for the optimization of the PVDF-based vibration sensors applicable in the efficient structural and health monitoring nanosystems.
\end{abstract}

Keywords: Nanosystem, vibration sensing, poly(vinylidene fluoride), crystallites, d33, electromechanical coupling

\section{INTRODUCTION}

At the present time, the increasing demand for the electrical energy is one of the most serious challenges that world faces. To cover this demand, fossil fuels, such as petroleum, coal and natural gas, are used as the main primary-energy source. The use of these traditional fuels is however connected to many environmental problems including air pollution, water pollution, or accidental oil spills [1,2]. From these reasons, there is an urgent need for the alternative energy sources. Probably, the most fascinating alternative concept to obtain energy is represented by the energy harvesting systems. Such devices utilize waste mechanical energy, such as vibrations, air/fluid movement, body motion etc., and converts it into the electrical form [3]. To construct the energy harvesting nanogenerator, various inorganic semi-conducting materials $(\mathrm{ZnO}, \mathrm{InN}, \mathrm{GaN}, \mathrm{CdS})$ or free ceramics $\left(\mathrm{NaNbO}_{3}, \mathrm{KNbO}_{3}\right)$ have been studied [4]. Although these materials demonstrated high efficiency, they are brittle, heavy and difficult to process, which limits the breadth of applications $[3,5]$. To eliminate these drawbacks, the materials of choice can be found in ferroelectric types of polymers, mainly poly(vinylidene fluoride) (PVDF) and its copolymers [6]. PVDF is a polymorphic material existing in five phases $(\alpha, \beta, \gamma, \delta$ and $\varepsilon$ ) depending on the processing methods. The $\alpha$ and $\varepsilon$-phases are non-polar due to the antiparallel packing of dipoles. On the other hand, the $\beta, y$ and $\delta$-phase are polar, and hence electroactive [7]. The $y$-phase of PVDF is referred to as the mixture of the $\alpha$ and $\beta$-phases, while $\delta$-phase is regarded as polar version of $\alpha$ phase. Amongst all conformations, the $\beta$-phase PVDF is the most desirable one for the construction of the 
energy harvesting and vibration sensing devices, since it exhibits the best piezoelectric properties $[8,9]$. The significant research efforts have been therefore targeted to facilitate formation of the $\beta$-phase content in PVDF. The $\beta$-phase can be obtained directly from the polymer melt, however, the process requires high temperature, high pressure and other specific conditions [9]. Conversely, the $\alpha$-phase can be obtained very easily, because it is the most stable primary phase of PVDF [10]. And subsequently, it can be transferred into the $\beta$-analogue by simple stretching (uniaxial or biaxial) at the elevated temperatures [11]. Other method to increment the $\beta$-phase content is through poling of the PVDF films in high external electric fields [12]. Also, the fabrication of films through electrospinning, which is also a form of mechanical elongation, was successfully applied [13]. Certain improvements in the $\alpha-\beta$-phase transformation were observed after the addition of graphene oxide or cellulose particles $[14,15]$.The $\beta$-phase is also achievable from the $\gamma$ and $\delta$-phase using a plethora of other processing techniques $[9,16]$. However, from the technological point of view, the uniaxial stretching is the most convenient method to convert the $\alpha$-phase into its electroactive $\beta$-counterpart. The stretching process of the PVDF was performed within wide temperature range $\left(50-150^{\circ} \mathrm{C}\right)$, with different stretching speeds $(1-1000 \mu \mathrm{m} / \mathrm{s})$ and various (1-5) stretching ratios [10]. Although the effects of these parameters on the formation of $\beta$-phase PVDF have been described, the implications of its molecular weight $(\mathrm{Mw})$ on the $\beta$-phase development, energy harvesting and vibration sensing capabilities have not been, surprisingly, addressed yet. Moreover, the $\mathrm{Mw}_{w}$ of the applied PVDF is hardly ever mentioned in the literature. This paper therefore aims to clarify the correlations between the Mw of the PVDF and the formation of the electroactive $\beta$-phase and consequential d33 coefficient after stretching at various uniaxial ratios.

\section{EXPERIMENTAL PART}

\subsection{Materials}

The PVDF beads (CAS number: 24937-79-9) of different average molecular weights (Mw); 71 000, 107000 and $530000 \mathrm{~g} / \mathrm{mol}$ (sample ID: M71, M107 and M530) were purchased from Sigma-Aldrich (USA). The density of beads was $1.78 \mathrm{~g} / \mathrm{cm}^{3}$ and they were used as received.

\subsection{Fabrication and stretching process}

The PVDF films with thickness of $0.8 \mathrm{~mm}$ were prepared using compression molding. In a typical procedure, the calculated mount of PVDF beads was placed into a mold, pre-heated (5 minutes) and compressed with a pressure of $10 \mathrm{MPa}$ (for additional 5 minutes), while the temperature was set to $210^{\circ} \mathrm{C}$. Afterwards, the mold was cooled down in a controlled manner to ensure repeatability of the process. The characterization/testing of the samples was performed at least $24 \mathrm{~h}$ after their successful fabrication.

The rectangular strips (dimensions of $10 \mathrm{~mm} \times 100 \mathrm{~mm}$ ) were cut out from PVDF films. Stretching of asprepared PVDF elements was performed using a tensile device M350-5 CT (Testometric, Lancashire, UK) coupled with a heat chamber (Omron) operating at a temperature of $65^{\circ} \mathrm{C}$. The cross-head speed of the clamps was set to $10 \mathrm{~mm} / \mathrm{min}$, with the relative elongations of $50,100,200,300$ and $500 \%$. In the case of M71, the elongation of $500 \%$ could not be achieved, since it was above its breaking point. Therefore, for this sample, we have selected the maximum elongation at $400 \%$.

\subsection{General characterization}

The crystalline phase development of PVDF films was studied via X-Ray diffractions (XRD) using Miniflex 600 (Rigaku, Japan) diffractometer with a Co-Ka radiation source $(\lambda=1.789 \AA)$ operating within $2 \theta$ range of 10 $95^{\circ}$ with a scan speed of $3^{\circ} / \mathrm{min}$. The Fourier transform infrared spectroscopy (FTIR) was performed on Nicolet 6700 (Thermo-Scientific, USA) spectrometer equipped with ATR accessory and a germanium crystal. The spectra were recorded in a wavenumber range of $4000-500 \mathrm{~cm}^{-1}$ with a spectral increment of $2 \mathrm{~cm}^{-1}$. Both analyzes were performed at laboratory conditions. 


\subsection{Energy harvesting setup}

Firstly, the poling of the stretched PVDF strips was performed using a custom-build apparatus at the electric field strength of $7 \mathrm{kV} / \mathrm{mm}$, and the temperature of $110^{\circ} \mathrm{C}$. Secondly, a thin conductive (silver) layer was deposited on the samples and their piezoelectric charge coefficient, d33, was measured within one hour after the poling process. The $\mathrm{d} 33$ was analyzed in the transversal mode using the electrometer 6517b (Keithley, USA). Each sample was placed between two copper electrodes; the lower electrode had a diameter of $20 \mathrm{~mm}$, while the upper one had a diameter of $10 \mathrm{~mm}$. A mechanical force of $0.49 \mathrm{~N}$ was applied onto the upper electrode and the electric charge generated by the sample was recorded. Each sample was analyzed at ten positions, the presented d33 values represent the average values from the obtained data.

\section{RESULTS AND DISCUSSION}

The PVDF strips of different $\mathrm{Mw}$ were stretched at the temperature of $65^{\circ} \mathrm{C}$ to generate the piezoelectric $\beta$ phase with subsequent poling process performed at $110^{\circ} \mathrm{C}$. The efficiency of phase transformation was determined by means of the FTIR spectroscopy. Figure 1 compares the FTIR spectra recorded for the M71, M107 and M530 samples. As clearly seen, the mechanical stretching significantly altered the FTIR profile indicating changes in the polymer chain conformations. In detail, the a-phase PVDF can be identified through a large number of characteristic peaks. In the studied wavenumber region, the relevant peaks of the $\alpha$-phase were centered at $762,795,855,974$ and $1210 \mathrm{~cm}^{-1}[2,17]$. After stretching, these peaks diminished giving rise to their electroactive $\beta$-phase counterparts centered at 840 and $1276 \mathrm{~cm}^{-1}[11]$.
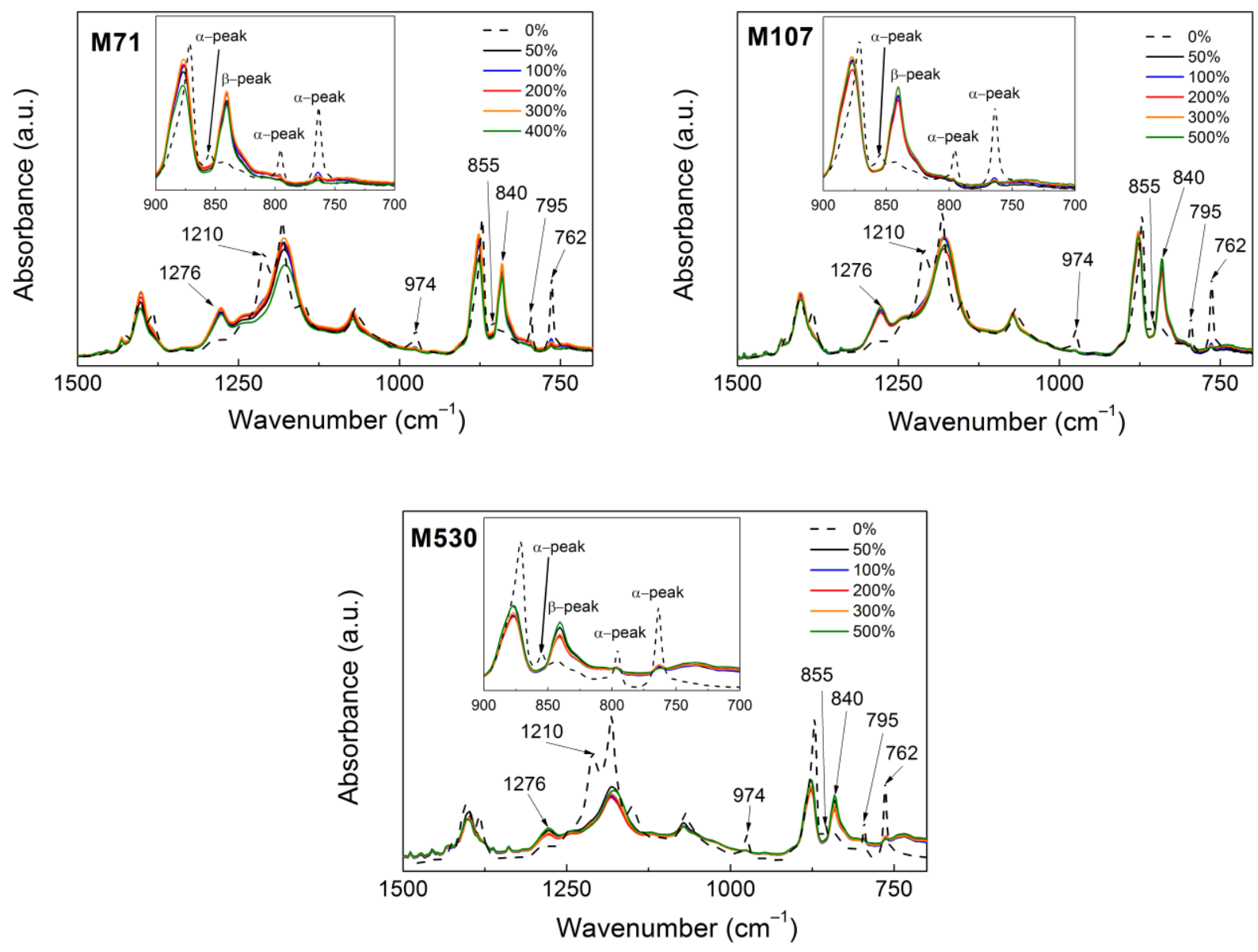

Figure 1 Comparison of the FTIR spectra for the PVDFs of different $\mathrm{Mw}$ 
The interpretation of peak at $840 \mathrm{~cm}^{-1}$ is not always straightforward; in some papers this peak is classified as pure $\beta$-phase [17], while in others it is considered as the $\beta$ - $\gamma$-phase mixture [18]. However, the signature of the $\gamma$-phase in terms of peaks at 776, 812, 833 and $1233 \mathrm{~cm}^{-1}$ was not identified. Also, the peak at $840 \mathrm{~cm}^{-1}$ was sharp without any distinct shoulder that would be coming from the $\mathrm{y}$-phase. Based on these findings, we tend to believe that the content of the $y$-phase in the PVDF was rather minimal.

The XRD is usually used as a complementary technique to determine the crystal phase of the PVDF. As shown in Figure 2, all samples exhibited typical XRD diffractograms ( $\mathrm{Ka}_{1}, \lambda=1.790 \AA$ ). Prior to stretching, the $\alpha$ phase was the most prevailing and exhibited typical double-peak corresponding to diffractions in planes (100) and (020), respectively. After the stretching, the $\beta$-phase was successfully developed, which was reflected in the single sharp peak that is assigned to the total diffraction in (110) and (200) planes [13]. The phase transformation was remarkably affected by the $M_{w}$ of the samples. For M71, the manifestation of the $\beta$-peak changed without any trend in peak intensity. In the samples M107 and M530, the intensity of the $\beta$-peak generally increased with the relative elongation, which implies a greater efficiency of the $\alpha$ - $\beta$-phase transformation. These results indicate that the $\mathrm{Mw}_{w}$ of the PVDF has a significant influence on the structural changes during the stretching process.
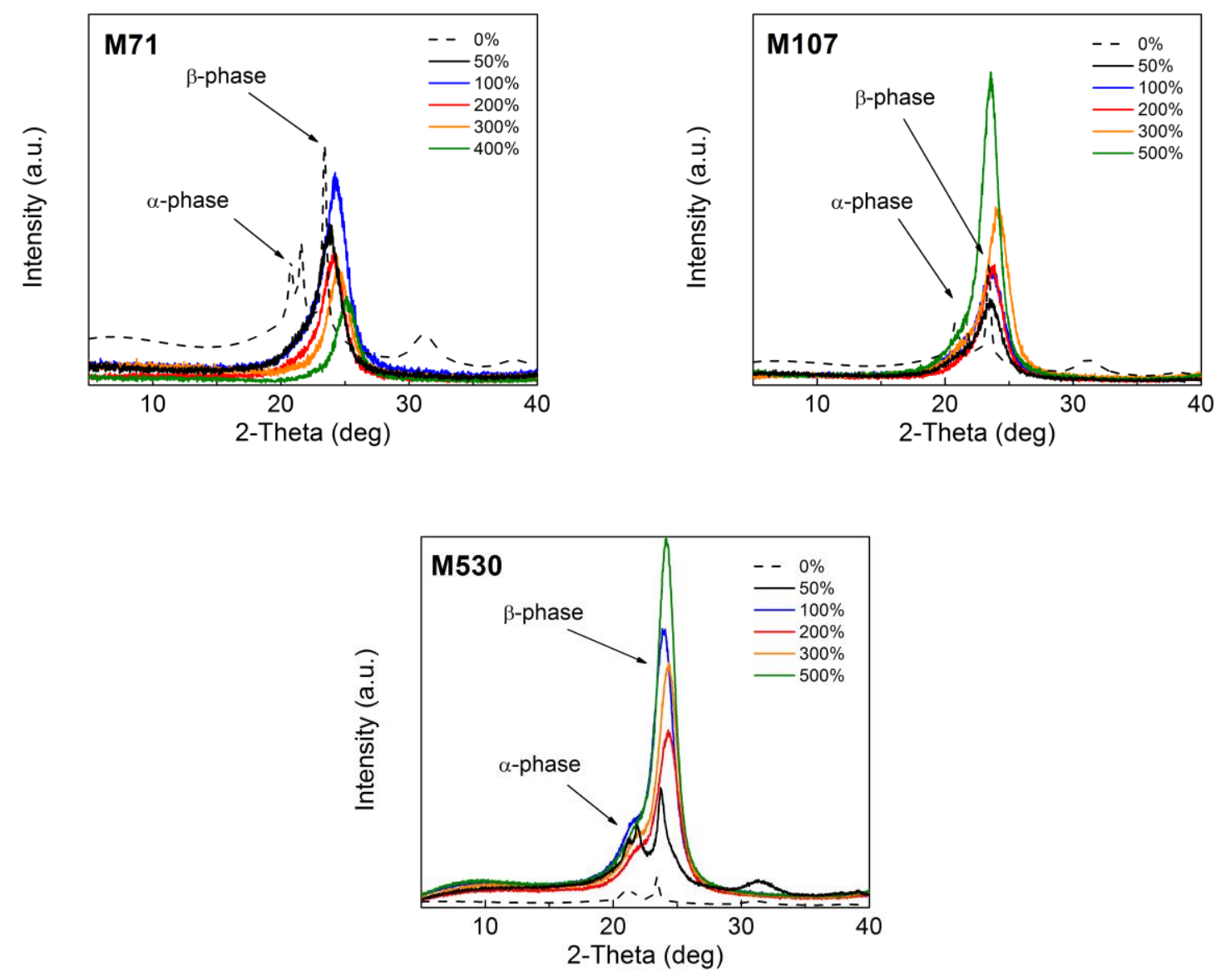

Figure 2 Comparison of the XRD patterns for the PVDFs of different $\mathrm{Mw}$

The electromechanical performance of the PVDF mainly depends on the $\beta$-phase content [12]. In our case, the formation of the $\beta$-phase was facilitated by stretching in a combination with poling process. Table 1 summarizes the d33 data for the investigated samples. It can be claimed that the applied stretching positively affected the d33 values, since they increased by a factor of 4-5 for the M71 and M530, when stretched from 50 to $500 \%$ relative elongation. The highest d33 value was however detected for the M107, which exhibited 
the $\mathrm{d} 33$ of $9.10 \mathrm{pC} / \mathrm{N}$ at maximal relative elongation. This value is below the theoretical $\mathrm{d} 33$ maximum that is over $25 \mathrm{pC} / \mathrm{N}$ for pure $\beta$-phase PVDF. Such difference indicates the persistent co-existence of the $\alpha$-phase, and the presence of trapped charges induced during the processing [19]. It should be mentioned that samples M107 and M530 have potential for further improvements since they have capability to achieve even higher relative elongations, and thus better conditions for the $\beta$-phase development. To conclude, we have shown that the Mw of the PVDF is highly important parameter affecting the $\mathrm{d} 33$ performance, and thus, it is of high relevancy for the fabrication of vibration sensing and energy harvesting elements.

Table 1 Summarized d33 values for the investigated PVDF samples

\begin{tabular}{|c|c|c|c|c|c|}
\hline Sample ID & $\mathbf{5 0} \%$ & $\mathbf{1 0 0} \%$ & $\mathbf{2 0 0} \%$ & $\mathbf{3 0 0} \%$ & $\mathbf{5 0 0} \%$ \\
\hline M71 & $1.20 \mathrm{pC} / \mathrm{N}$ & $5.10 \mathrm{pC} / \mathrm{N}$ & $5.62 \mathrm{pC} / \mathrm{N}$ & $6.20 \mathrm{pC} / \mathrm{N}$ & $* 6.50 \mathrm{pC} / \mathrm{N}$ \\
\hline M107 & $7.00 \mathrm{pC} / \mathrm{N}$ & $7.80 \mathrm{pC} / \mathrm{N}$ & $7.60 \mathrm{pC} / \mathrm{N}$ & $8.50 \mathrm{pC} / \mathrm{N}$ & $9.10 \mathrm{pC} / \mathrm{N}$ \\
\hline M530 & $2.00 \mathrm{pC} / \mathrm{N}$ & $4.18 \mathrm{pC} / \mathrm{N}$ & $3.20 \mathrm{pC} / \mathrm{N}$ & $3.60 \mathrm{pC} / \mathrm{N}$ & $8.20 \mathrm{pC} / \mathrm{N}$ \\
\hline
\end{tabular}

*the value taken for sample with the relative elongation of $400 \%$

\section{CONCLUSION}

In this study, the PVDF strips of different $M w$ were stretched and subjected to poling in order to facilitate formation of the piezoelectric $\beta$-phase. The phase transformation was monitored using FTIR spectroscopy demonstrating the changeover between the dominating peaks of the $\alpha$ and $\beta$-phase at $762 \mathrm{~cm}^{-1}$ and $840 \mathrm{~cm}^{-1}$, respectively. Also, the XRD data showed the successful $\beta$-phase development. In particular, samples M107 and M530 exhibited increasing peak-signal intensity with the relative elongation. The implications of different $\mathrm{M}_{\mathrm{w}}$ of the samples were reflected in the $\mathrm{d} 33$ values that exhibited significant variations. Samples M71 and M530 experienced several-fold increase in the electromechanical performance, however, the highest value of the $\mathrm{d} 33$ was $9.10 \mathrm{pC} / \mathrm{N}$ generated by the $\mathrm{M} 107$. Based on these preliminary findings, further research is clearly required to better understand the interrelations among the $\mathrm{Mw}$, relative elongation, crystallinity, poling conditions and d33 value of the PVDF-based nanosystems.

\section{ACKNOWLEDGEMENTS}

The authors gratefully acknowledge the Czech Science Foundation (grant no. 19-17457S) for the financial support. This work was also supported by the Ministry of Education, Youth and Sports of the Czech Republic - DKRVO (RP/CPS/2020/003) and (RP/CPS/2020/006).

\section{REFERENCES}

[1] FRAGOULI, D., ATHANASSIOU, A. Oil spill recovery: Graphene heaters absorb faster. Nature Nanotechnology. 2017, vol. 12, no. 5, pp. 406-407.

[2] GAUR, A., TIWARI, S., KUMAR, C., MAITI, P. A bio-based piezoelectric nanogenerator for mechanical energy harvesting using nanohybrid of poly(vinylidene fluoride). Nanoscale Advances. 2019, vol. 1, no. 8, pp. 3200-3011.

[3] GAUR, A., KUMAR, C., TIWARI, S., MAITI, P. Efficient energy harvesting using processed poly(vinylidene fluoride) nanogenerator. ACS Applied Energy Materials. 2018, vol. 1, no. 7, pp. 3019-3024.

[4] ZENG, W., TAO, X.M., CHEN, S., SHANG, S.M., CHAN, H.L.W., CHOY, S.H. Highly durable all-fiber nanogenerator for mechanical energy harvesting. Energy \& Environmental Science. 2013, vol. 6, no. 9, pp. 26312638.

[5] WANKHADE, S.H., TIWARI, S., GAUR, A., MAITI, P. PVDF-PZT nanohybrid based nanogenerator for energy harvesting applications. Energy Reports. 2020, vol. 6, pp. 358-364. 
[6] RAMADAN, K.S., SAMEOTO, D., EVOY, S. A review of piezoelectric polymers as functional materials for electromechanical transducers. Smart Materials and Structures. 2014, vol. 23, no. 3, 03301.

[7] MARTIN, J., ZHAO, D., LENZ, T., KATSOURAS, I., DE LEEUW, D.M., STINGELIN, N. Solid-state-processing of delta-PVDF. Materials Horizons. 2017, vol. 4, no. 3, pp. 408-414.

[8] EL MOHAJIR, B.E., HEYMANS, N. Changes in structural and mechanical behaviour of PVDF with processing and thermomechanical treatments. 1. Change in structure. Polymer. 2001, vol. 42, no. 13, pp. 5661-5667.

[9] RUAN, L.X., YAO, X.N., CHANG, Y.F., ZHOU, L.Q., QIN, G.W., ZHANG, X.M. Properties and applications of the beta phase poly(vinylidene fluoride). Polymers. 2018, vol. 10, no. 3, 228.

[10] LI, L., ZHANG, M.Q., RONG, M.Z., RUAN, W.H. Studies on the transformation process of PVDF from alpha to beta phase by stretching. RSC Advances. 2014, vol. 4, no. 8, pp. 3938-3943.

[11] MOHAMMADI, B., YOUSEFI, A.A., BELLAH, S.M. Effect of tensile strain rate and elongation on crystalline structure and piezoelectric properties of PVDF thin films. Polymer Testing. 2007, vol. 26, no. 1, pp. 42-50.

[12] SHARMA, M., MADRAS, G., BOSE, S. Process induced electroactive beta-polymorph in PVDF: Effect on dielectric and ferroelectric properties. Physical Chemistry Chemical Physics. 2014, vol. 16, no. 28, pp. 1479214799.

[13] FANG, J., NIU, H.T., WANG, H.X., WANG, X.G., LIN, T. Enhanced mechanical energy harvesting using needleless electrospun poly(vinylidene fluoride) nanofibre webs. Energy \& Environmental Science. 2013, vol. 6, no. 7, pp. 2196-2202.

[14] ISSA, A.A., AL-MAADEED, M.A.A.S, MRLIK, M., LUYT, A.S. Electrospun PVDF graphene oxide composite fibre mats with tunable physical properties. Journal of Polymer Research. 2016, vol. 23, 232.

[15] ISSA, A.A., AL-MAADEED, M.A.A.S, LUYT, A.S., MRLIK, M., HASSAN, M.K. Investigation of the physicomechanical properties of electrospun PVDF/cellulose (nano)fibers. Journal of Applied Polymer Science. 2016, vol. 133, 43594.

[16] FLORCZAK, S., LORSON, T., ZHENG, T., MRLIK, M., HUTMACHER, D.W., HIGGINS, M.J., LUXENHOFER, R., DALTON, P.D. Melt electrowriting of electroactive poly(vinylidene difluoride) fibers. Polymer International. 2019, vol. 68, no. 4, pp. 735-745.

[17] MARTINS, P., LOPES, A.C., LANCEROS-MENDEZ, S. Electroactive phases of poly(vinylidene fluoride): Determination, processing and applications. Progress in Polymer Science. 2014, vol. 39, pp. 683-706.

[18] GREGORIO, R., CAPITAO, R.C. Morphology and phase transition of high melt temperature crystallized poly(vinylidene fluoride). Journal of Materials Science. 2010, vol. 35, pp. 299-306.

[19] GOMES, J., SERRADO NUNES, J., SENCADAS, V., LANCEROS-MENDEZ, S. Influence of the $\beta$-phase content and degree of crystallinity on the piezo- and ferroelectric properties of poly(vinylidene fluoride). Smart Materials and Structures. 2010, vol. 19, 065010. 